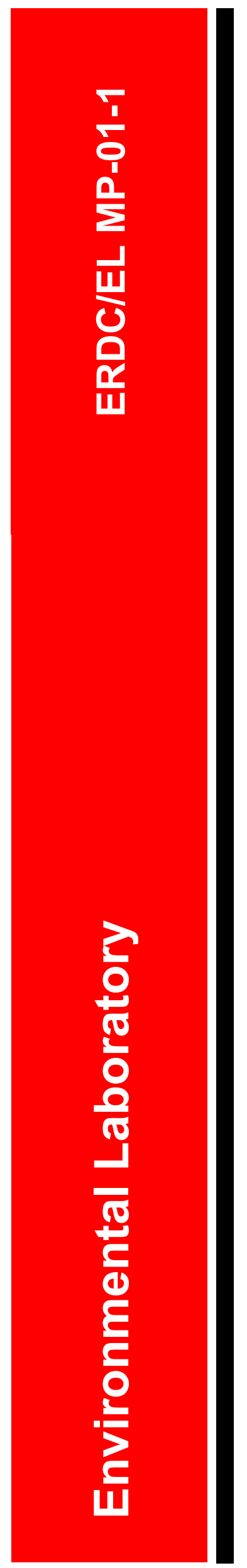

\title{
Assessing the Effect of Estimation Error on Population Viability Analysis: An Example Using the Black-Capped Vireo
}

Pablo Parysow and David J. Tazik

August 2001 
The contents of this report are not to be used for advertising, publication, or promotional purposes. Citation of trade names does not constitute an official endorsement or approval of the use of such commercial products.

The findings of this report are not to be construed as an official Department of the Army position, unless so designated by other authorized documents. 


\title{
Assessing the Effect of Estimation Error on Population Viability Analysis: An Example Using the Black-Capped Vireo
}

\author{
by Pablo Parysow \\ School of Forestry \\ Northern Arizona University \\ P.O. Box 15018 \\ Flagstaff, AZ 86011 \\ David J. Tazik \\ U.S. Army Engineer Research and Development Center \\ Environmental Laboratory \\ 3909 Halls Ferry Road \\ Vicksburg, MS 39180-6199
}

Final report

Approved for public release; distribution is unlimited 


\section{Contents}

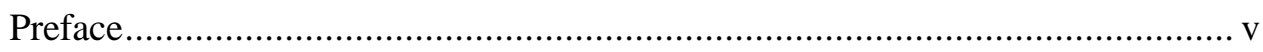

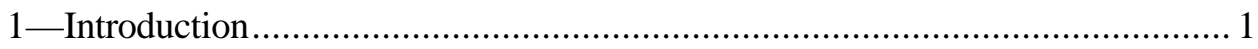

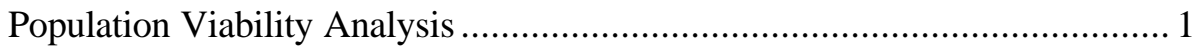

Black-Capped Vireo........................................................................ 3

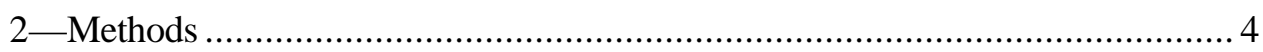

Simulation Under the Assumption of No Uncertainty ................................ 4

Simulation Accounting for Uncertainty ................................................. 6

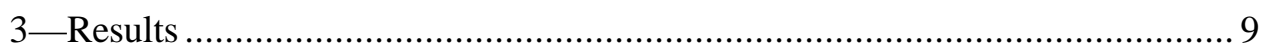

Simulation Under the Assumption of No Uncertainty .............................. 9

Simulation Accounting for Uncertainty ................................................ 10

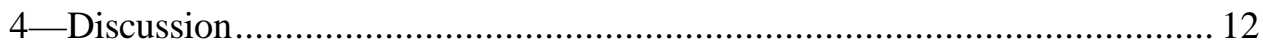

5-Conclusions/Management Implications..................................................... 17

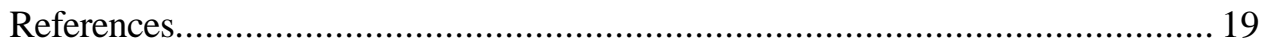

SF 298

\section{List of Figures}

Figure 1. Probability of persistence over 100 years under the nouncertainty assumption for both unmanaged and conservation scenarios 9

Figure 2. Expected heterozygosity retained over 100 years under the no-uncertainty assumption for both unmanaged and conservation scenarios

Figure 3. Probability of persistence at the end of 100 years as a function of different levels of fecundity when accounting for uncertainty 
Figure 4. Expected heterozygosity retained at the end of 100 years as a function of different levels of fecundity when accounting for uncertainty

Figure 5. Hypothetical representation of the unmanaged and conservation scenarios with respect to probability of persistence assuming no estimate uncertainty

Figure 6. Hypothetical representation of explicitly adding uncertainty in estimates of factors out of management control to the conservation scenario under no uncertainty displayed in Figure 5

Figure 7. Hypothetical representation of establishing conservation management objectives to achieve the persistence goal in spite of uncertainty in parameter estimates of factors out of management control 


\section{Preface}

This study was conducted by the authors during 1997 while at the Construction Engineering Research Laboratory (CERL), U.S. Army Engineer Research and Development Center (ERDC), under the Environmental Quality Technology Program, Threatened and Endangered Species Project. The purpose was to quantitatively assess the impact of error and uncertainty on the evaluation of endangered species population viability.

Authors of this report were Pablo Parysow, Northern Arizona University, Flagstaff, AZ, and David J. Tazik, Environmental Laboratory, ERDC, Vicksburg, MS.

The authors thank personnel of Fort Hood, Texas, CERL, and the Strategic Environmental Research and Development Program for providing support during this study. Thanks to Tim Hayden and Howard Weinberg (CERL) for their helpful comments and suggestions. Finally, we gratefully acknowledge Ken Paige, University of Illinois, Jeff Brawn, Illinois Natural History Survey, George Gertner, University of Illinois, Jean O'Neil, EL, Rich Fischer, EL, Mike Passmore, EL, Dick Kasul, EL, Barry Brook, Northern Territory University, Australia, and Resit Akcakaya, Applied Biomathematics, for critically reviewing previous drafts of this manuscript.

During the conduct of the study Dr. Michael O'Connor was Director, CERL, and Dr. William Severinghaus was Chief, Land Management Laboratory. At the time of publication, Dr. Edwin A. Theriot was Director of EL.

During publication of this report, Dr. James R. Houston was Director of ERDC, and COL John W. Morris III, EN, was Commander.

This report should be cited as

Parysow, P., and Tazik, D. J. (2001). "Assessing the effect of estimation error on population viability analysis: An example using the black-capped vireo," ERDC/EL MP-01-1, U.S. Army Engineer Research and Development Center, Vicksburg, MS.

The contents of this report are not to be used for advertising, publication, or promotional purposes. Citation of trade names does not constitute an official endorsement or approval of the use of such commercial products. 


\section{Introduction}

\section{Population Viability Analysis}

Population viability analysis (PVA) is widely applied to assess extinction probabilities and loss of genetic diversity (Soulé 1987, Lindenmayer et al. 1993) in endangered wildlife populations. This approach allows wildlife managers to simulate extinction processes that act on small populations of organisms, and therefore to assess their long-term viability (Clark, Backhouse, and Lacy 1991; Crone and Gehring 1998). PVA is typically carried out through Monte Carlo computer simulations employing a model that accounts for the average condition as well as natural variability (stochasticity) of the factors that influence population dynamics. Therefore, this type of analysis may also be viewed as a form of risk assessment in biological conservation (Ginzburg et al. 1982). Information required by these studies usually includes fecundity, mortality, carrying capacity, metapopulation structure, natural variation in life history attributes, as well as probability and effect of catastrophes. A plethora of PVA model building tools are now available including ALEX (Possingham and Davies 1995), GAPPS (Harris, Metzger, and Bevins 1986), INMAT (Mills and Smouse 1994), POPGEN (Kelly and Durant 2000), RAMAS (Ferson and Akçakaya 1989, Akçakaya 1998, Ferson 1990), and VORTEX (Lacy 1993) (see reviews by Boyce (1992) and Beissinger and Westphal (1998) for further background). Brook, Burgman, and Frankham (2000) compared historical information with predictions from five of these commonly used PVA models and concluded that results produced were not only remarkably similar across models, but also that PVA predictions are expected to be relatively accurate given adequate model input data.

PVA is often used to assess the likely future of endangered species and, if needed, to recommend management objectives intended to achieve relevant conservation goals. Conservation goals may vary in different cases, but the following are commonly applied in PVA: probability of persistence and retention of genetic diversity (expressed as expected heterozygosity) of at least 95 percent and 90 percent, respectively, over the next 100 years (e.g., Shaffer 1987, Soulé et al. 1986). Despite its widespread use, some of the standard applications and assumptions for conducting PVA have been questioned (Brook 2000, Caughley 1994, Taylor 1995, White 2000). In particular, since PVA focuses on single species, this approach should be combined with an ecosystem-level strategy to enhance the effectiveness of the conservation effort (e.g., Meffe and Carroll 1994). 
In the present study, stochasticity refers only to natural variation of model factors caused by environmental, demographic, and genetic variability. In contrast, uncertainty refers only to estimation error in parameter estimates of model factors. A parameter characterizes the true value of a model factor, whereas a parameter estimate represents the best approximation to that true value based on available knowledge. Uncertainty in parameter estimates arises from limitations of the methods used to estimate parameter values, such as sampling error, measurement error, expert opinion error, etc. In that regard, Kendall (1998) indicated the importance of separating stochasticity from uncertainty when estimating vital rates, whereas White (2000) addressed approaches for accomplishing that objective. Unfortunately, the concepts of stochasticity and uncertainty are inconsistently applied throughout the literature (e.g., see use in Burgman, Ferson, and Akçakaya (1993) as opposed to Rossing, Daamen, and Jansen (1994a,b) and Committee on Applications of Ecological Theory to Environmental Problems (1986)). However, based on the definitions provided above, we can state that while stochasticity is usually accounted for in PVA, uncertainty is not, such that values of factors representing average conditions as well as natural variability are assumed to be true or free of estimation error. This approach will be referred to here as the "no-uncertainty assumption."

Nevertheless, under a more realistic view, error associated with parameter estimates of all those factors should be accounted for explicitly.

Natural resource managers frequently make decisions based on incomplete information about the system that they are working in (Soulé 1985, Diamond 1986). In that regard, Clark, Warneke, and George (1990) suggested that management usually involves uncertainty, and that identifying the sources and consequences of uncertainty constitute very important management information. Moreover, consistent and explicit treatment of uncertainty is essential to ensuring defensible environmental management decisions (Marshall, Haight, and Homans 1998).

Both data and theory employed in PVA contain some degree of uncertainty (Shaffer 1990, Mace and Lande 1991, Primack 1993). Lindenmayer et al. (1993) stated that PVA data are often unavailable or incomplete, and stressed the significance of not only identifying important factors that deserve thorough study but also obtaining accurate parameter estimates. Likewise, Mattson and Craighead (1994) emphasized the critical importance of developing a protocol that incorporates uncertainty into parameter estimation and management of endangered species. Lastly, Boyce (1992) suggested that error propagation may be assessed by simulation methods, whereas Botsford and Brittnacher (1998) and White (2000) indicated that analyses that do not account for uncertainty can underestimate the probability of extinction.

One of the approaches for addressing error in PVA consists of using minimum, average, and maximum values as parameter estimates (Hamilton and Moller 1995, Marmontel, Humphrey, and O'Shea 1997). On the other hand, Ludwig (1996) compared maximum likelihood and Bayesian approaches to assessing risk of extinction under uncertainty in parameter estimates in a simple regression model, and concluded that maximum likelihood and similar methods 
grossly underestimate the risk of early population collapse. Finally, and partly analogous to the method proposed and implemented in this study, White (2000) suggested that a simulation method based on running numerous PVA using different possible sets of parameter estimates would allow one to obtain a probability of persistence and its confidence interval as a function of estimate uncertainty.

Models employed in conservation (as well as in many other ecological applications) are idealized and simplistic versions of the processes involved. This study, however, does not attempt to account for model uncertainty. The objective of the present study is to demonstrate one approach for incorporating uncertainty in PVA and assessing its impact on establishing specific management objectives. Here, PVA was applied to a single population of black-capped vireo (Vireo atricapillus), a species familiar to us from related field research activities sponsored by the U.S. Army at Fort Hood, Texas.

\section{Black-Capped Vireo}

The black-capped vireo is one of approximately 260 neotropical migrant land bird species (Dobkin 1994) that breed in North America and migrate primarily to Central and South America during the winter. The black-capped vireo was listed as an endangered species by the U.S. Fish and Wildlife Service in 1987 (Ratzlaff 1987) and has been the subject of a number of studies that evaluated factors threatening its persistence (Graber 1957, 1961; Tazik 1991; Grzybowski, Tazik, and Schnell 1994). Grzybowski (1995) summarizes the life history and ecology of this species.

Habitat destruction, low fecundity (mainly caused by brown-headed cowbird [Molothrus ater] parasitism), and harassment by birders are believed to be the main causes of the decline of this species (Ratzlaff 1987). The recovery priority of the black-capped vireo was classified by the U.S. Fish and Wildlife Service (1991) as 2C, which characterizes a species with a high degree of threat, high potential for recovery, and in conflict with construction or development projects or other forms of economic activity. Reed (1992) assigned rank 1 to this species, which characterizes the most vulnerable group of neotropical migrant birds, taking into account range, habitat specificity, geographic distribution, and existence of large populations. 


\section{Methods}

A PVA was conducted for the black-capped vireo using available knowledge to assign values to all model factors based on Graber $(1957,1961)$, Tazik (1991), Grzybowski, Tazik, and Schnell (1994), Grzybowski (1995), and expert opinion. The computer simulation program VORTEX (Lacy 1993), version 6.30, was used for all simulations. VORTEX was selected because it not only incorporates the fundamental factors for modeling small populations, but this program is also among the most widely used tools for conducting PVA (Caughley 1994).

VORTEX is an individual-based population model that simulates the fate of small populations by accounting for mate selection, reproduction, mortality, metapopulation dynamics, supplementation, harvesting, carrying capacity, occurrence of catastrophes, as well as genetic, demographic, and environmental stochasticity. While other PVA software might yield different quantitative results (Mills et al. 1996, Brook et al. 1997, Brook, Burgman, and Frankham 2000), the general approach and conclusions are expected to be comparable (Brook et al. 2000).

Two main situations were simulated regarding estimation error: one assuming no uncertainty, the other accounting for uncertainty. In turn, scenarios relevant to conservation analysis were simulated under each of these two error assumptions as explained in the following sections.

\section{Simulation Under the Assumption of No Uncertainty}

Scenarios in this section were run based on the assumption that values of factors in the PVA model have no estimation error. The first scenario consisted of the premise that neither conservation measures nor changes in the current environmental conditions and trends would take place over the simulated 100-year period. This set of conditions is referred to as the "unmanaged scenario."

Parameter estimates for one black-capped vireo population were obtained based on our best currently available knowledge on this species and its environment. Those estimates are presented in Table 1 (VORTEX factors not included in this table were not accounted for in this study). This unmanaged scenario was carried out through 2,000 stochastic simulation runs. 


\begin{tabular}{|c|c|}
\hline \multicolumn{2}{|c|}{$\begin{array}{l}\text { Table } 1 \\
\text { Values Entered into VORTEX to Characterize the Unmanaged } \\
\text { Scenario }\end{array}$} \\
\hline Factor & Value \\
\hline $\begin{array}{l}\text { Environmental variation in reproduction and mortality } \\
\text { will be }\end{array}$ & Uncorrelated \\
\hline Types of catastrophes & 1 \\
\hline Mating system & Monogamous \\
\hline $\begin{array}{l}\text { Age in which individuals of each sex normally begin } \\
\text { breeding }\end{array}$ & $\begin{array}{l}\text { Females: } 1 \text { year } \\
\text { Males: } 1 \text { year }\end{array}$ \\
\hline Age beyond which all animals die & 9 years \\
\hline Proportion of males at birth & 0.50 \\
\hline Maximum number of young per female per season & 8 \\
\hline Reproduction is assumed to be density & Independent \\
\hline Percentage of brood sizes & $\begin{array}{l}\text { Zero: } 62.60 \% \\
\text { The remainder distribution was assigned } \\
\text { discretionary values to obtain a fecundity level } \\
\text { equal to } 0.80 \text { young fledged per female per } \\
\text { year }\end{array}$ \\
\hline $\begin{array}{l}\text { Standard deviation due to environmental variation of } \\
\text { percentage of breeding females }\end{array}$ & 35.21 \\
\hline $\begin{array}{l}\text { Percentage mortality by age and sex in immature } \\
\text { individuals }\end{array}$ & $\begin{array}{l}\text { Females: } 57.00 \% \\
\text { Males: } 57.00 \% \\
\end{array}$ \\
\hline $\begin{array}{l}\text { Standard deviation due to environmental variation of } \\
\text { percentage mortality by age and sex in immature } \\
\text { individuals }\end{array}$ & $\begin{array}{l}\text { Females: } 13.61 \\
\text { Males: } \quad 13.61\end{array}$ \\
\hline Percentage mortality in adults for each sex & $\begin{array}{l}\text { Females: } 43.00 \% \\
\text { Males: } 35.48 \%\end{array}$ \\
\hline $\begin{array}{l}\text { Standard deviation due to environmental variation of } \\
\text { percentage mortality in adults for each sex }\end{array}$ & $\begin{array}{l}\text { Females: } 10.27 \\
\text { Males: } 8.47 \\
\end{array}$ \\
\hline Probability of occurrence of a catastrophe & $5 \%$ \\
\hline Severity of a catastrophe with respect to reproduction & 0.65 \\
\hline Severity of a catastrophe with respect to survival & 0.65 \\
\hline Percentage of males in the breeding pool & $83.80 \%$ \\
\hline Initial population size & 3,367 (following a stable age distribution) \\
\hline Carrying capacity & 6,313 individuals \\
\hline $\begin{array}{l}\text { Expected rate of change in carrying capacity over a } \\
\text { specified period }\end{array}$ & $-2.2 \%$ per year over 100 years \\
\hline
\end{tabular}

If either of two commonly applied conservation goals, namely probability of persistence of at least 95 percent and retention of genetic diversity (expressed as expected heterozygosity) of at least 90 percent over the next 100 years, was not achieved, "conservation scenarios" would be simulated so as to reach those goals. Two key factors modifiable as management objectives for this species are fecundity and carrying capacity. Fecundity in the black-capped vireo depends largely on the degree to which cowbird parasitism can be controlled. Carrying capacity depends on the amount of available habitat. The chosen conservation scenarios would be as follows: carrying capacity was to be maintained constant at the current level, whereas fecundity would be increased in steps of 0.1 starting from a base of 0.8 young per female per year (fecundity under the unmanaged scenario) until the two conservation goals were achieved. Incidentally, evidence from limited field data also indicates that following implementation of cowbird control, natural variability of the percentage of breeding females declined to 9.11, whereas the percentage of nonbreeding females declined to 26.57. Therefore, 
these latter values would also be employed in the conservation simulations. Again, 2,000 stochastic simulation runs would be carried out to evaluate each conservation scenario.

\section{Simulation Accounting for Uncertainty}

The strategy proposed to account for uncertainty in parameter estimates consists of running numerous entire standard PVA. In each of those PVA, factors depicting both average conditions and stochasticity take on parameter estimates that represent only one set of possible true parameter values. Those estimates, in turn, are randomly and independently sampled from the corresponding error probability density functions. Accordingly, if either the probability of persistence or retention of expected heterozygosity achieved across all those standard PVA is lower than the conservation goals, the entire simulation analysis is repeated after establishing more demanding management objectives for the factors under management control. This process continues until all conservation goals are achieved.

In the absence of statistical error estimates for the black-capped vireo PVA, maximum uncertainty was assigned to parameter estimates through the so-called noninformative prior uniform distribution (e.g., Box and Tiao 1973, Goovaerts 1997). Estimation error was only assigned to factors out of management control that take on numerical values, with the following eceptions: (a) types of catastrophes are assumed known; (b) age in which individuals of each sex normally begin breeding is a well-known value for the black-capped vireo; and (c) maximum number of young per female per season is not relevant considering the approach taken to model fecundity. The upper and lower bounds believed to characterize the range of possible true parameters of the remaining factors are listed in Table 2. Characterization of estimation error was carried out through the beta distribution (e.g., Hogg and Tanis 1988). This distribution was used because it is: (a) flexible, and thus able to characterize different levels of uncertainty (the uniform distribution being one special case); and (b) bounded at both extremes, which ensures that the values generated will originate from within the specified possible range.

The first set of simulations would consist of running 100 standard PVA generated by adding uncertainty to the conservation scenario that achieved the conservation goals under the no-uncertainty assumption. Estimates of the factors out of management control in each of those PVA would be sampled from the uniform distributions given by the bounds provided in Table 2 . The range of population dynamics given by the resulting estimates of average conditions and natural variability within each of those 100 standard PVA would in turn be simulated through 100 stochastic simulation runs. 


\begin{tabular}{|c|c|c|}
\hline \multicolumn{3}{|c|}{$\begin{array}{l}\text { Table } 2 \\
\text { Upper and Lower Bounds for the Estimates of Factors Out of } \\
\text { Management Control }\end{array}$} \\
\hline Factor & Lower Bound & Upper Bound \\
\hline Age beyond which all animals die & 6 years & 12 years \\
\hline Proportion of males at birth & 0.35 & 0.65 \\
\hline $\begin{array}{l}\text { Percentage mortality by age and sex in immature } \\
\text { individuals }\end{array}$ & $\begin{array}{l}\text { Females: } 48.00 \% \\
\text { Males: } \quad 48.00 \%\end{array}$ & $\begin{array}{l}\text { Females: } 66.00 \% \\
\text { Males: } \quad 66.00 \%\end{array}$ \\
\hline $\begin{array}{l}\text { Standard deviation due to environmental variation } \\
\text { of percentage mortality by age and sex in immature } \\
\text { individuals }\end{array}$ & $\begin{array}{ll}\text { Females: } & 7.61 \\
\text { Males: } & 7.61\end{array}$ & $\begin{array}{lr}\text { Females: } & 19.61 \\
\text { Males: } & 19.61\end{array}$ \\
\hline Percentage mortality in adults for each sex & $\begin{array}{l}\text { Females: } 33.00 \% \\
\text { Males: } \quad 28.48 \%\end{array}$ & $\begin{array}{l}\text { Females: } 53.00 \% \\
\text { Males: } \quad 42.48 \%\end{array}$ \\
\hline $\begin{array}{l}\text { Standard deviation due to environmental variation } \\
\text { of percentage mortality in adults for each sex }\end{array}$ & $\begin{array}{ll}\text { Females: } 5.27 \\
\text { Males: } \quad 3.47\end{array}$ & $\begin{array}{lc}\text { Females: } & 15.27 \\
\text { Males: } & 13.47\end{array}$ \\
\hline Probability of occurrence of a catastrophe & $1 \%$ & $9 \%$ \\
\hline $\begin{array}{l}\text { Severity of a catastrophe with respect to } \\
\text { reproduction }\end{array}$ & 0.45 & 0.85 \\
\hline Severity of a catastrophe with respect to survival & 0.45 & 0.85 \\
\hline Percentage of males in the breeding pool & $71.80 \%$ & $95.80 \%$ \\
\hline Initial population size & $\begin{array}{l}1,734 \text { (following a } \\
\text { stable age distribution) }\end{array}$ & $\begin{array}{l}5,000 \text { (following a } \\
\text { stable age distribution) }\end{array}$ \\
\hline Carrying capacity & 5,000 individuals & 7,626 individuals \\
\hline
\end{tabular}

If conservation goals could not be achieved at first, the same simulation strategy would be implemented again after establishing more demanding objectives for the factors under management control. If needed, this approach would be consecutively applied until all the conservation goals were reached. In these scenarios, carrying capacity would also be maintained constant at the current level, whereas fecundity would be increased in steps of 0.1 . Here, too, 100 standard PVA (with 100 stochasticity runs per PVA) would be conducted for each fecundity level. This stepwise procedure may be illustrated as follows:

- Step 1: Set Initial Management Objectives. Establish objectives that meet conservation goals not accounting for uncertainty. In this case: constant carrying capacity, and fecundity of 2.5 young per female per year (as shown below in the Results chapter).

- Step 2: Uncertainty Monte Carlo Simulation (100 iterations). In each iteration, generate one parameter estimate for each factor out of management control by sampling from its beta distribution.

- Step 2.1: Stochastic Monte Carlo Simulation (100 iterations). Simulate range of population dynamics using average conditions as well as demographic, environmental, and genetic stochasticity from parameter estimates generated in Step 2.

\section{- Step 2.2: End Stochastic Monte Carlo Simulation Iteration.}

- Step 3: End Uncertainty Monte Carlo Simulation Iteration. 
- Step 4: Evaluate Management Strategy. If conservation goals are met across all uncertainty Monte Carlo simulation iterations, go to Step 6. If not, go to Step 5 .

- Step 5: Set More Demanding Management Objectives. In this case: increment fecundity by 0.1 young per female per year. Go to Step 2 .

- Step 6: Select Final Management Objectives. Management objectives that achieved conservation goals under uncertainty are selected. In this case: final fecundity rate of 3.5 young per female per year and constant carrying capacity. 


\section{Results}

\section{Simulation Under the Assumption of No Uncertainty}

\section{Unmanaged scenario}

In the unmanaged scenario under the assumption of no uncertainty, the population went extinct in every simulation run. Therefore, both probability of persistence and expected heterozygosity retained at the end of the next 100 years were equal to zero (Figures 1 and 2). The mean time to extinction was 17.8 years.

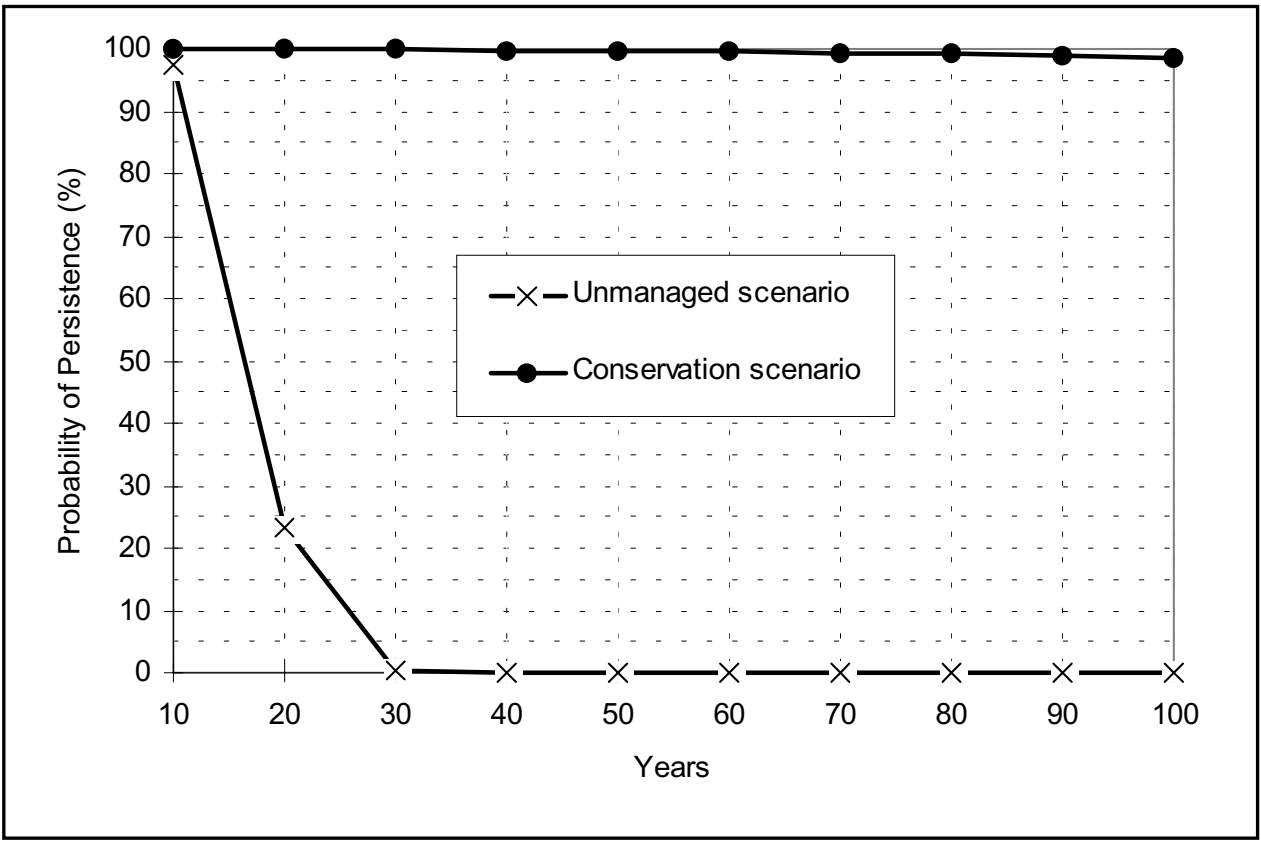

Figure 1. Probability of persistence over 100 years under the no-uncertainty assumption for both unmanaged and conservation scenarios 


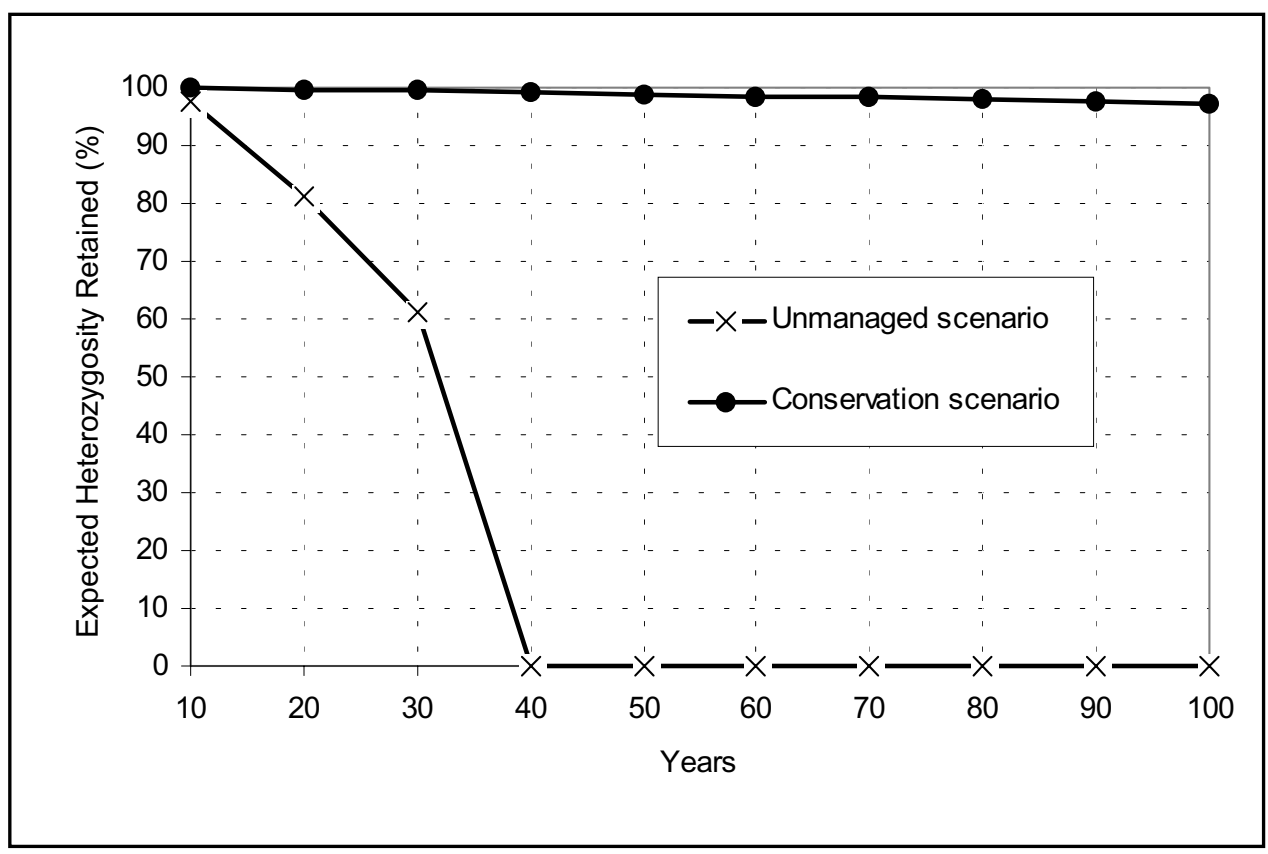

Figure 2. Expected heterozygosity retained over 100 years under the nouncertainty assumption for both unmanaged and conservation scenarios

\section{Conservation scenario}

The conservation goals were met when fecundity was set to 2.5 young fledged per female per year with carrying capacity held constant. This scenario produced a probability of persistence equal to 98.7 percent (Figure 1), whereas the final expected heterozygosity retained was equal to 97.3 percent (Figure 2). These levels of fecundity and carrying capacity constitute the management objectives required to meet the conservation goals under the no-uncertainty assumption. In addition, the lower variability in the percentage of breeding females achieved through cowbird control described earlier is likely to have also played a role in the achievement of the conservation goals, thus becoming a collateral management objective as well.

\section{Simulation Accounting for Uncertainty}

The first set of simulations under conditions of uncertainty, with carrying capacity constant and fecundity set to 2.5 (fecundity objective under the nouncertainty assumption), resulted in an average probability of persistence of 58.2 percent, and retention of expected heterozygosity of 78.1 percent, both short of the established conservation goals. In the second series of simulations, fecundity was incremented in steps of 0.1 until both conservation goals were achieved. Both conservation goals were only achieved when fecundity equaled 3.5 young fledged per female per year (Figures 3 and 4). Specifically, this last set of simulations produced an average probability of persistence equal to 95.4 percent and retention of expected heterozygosity of 97.6 percent. 


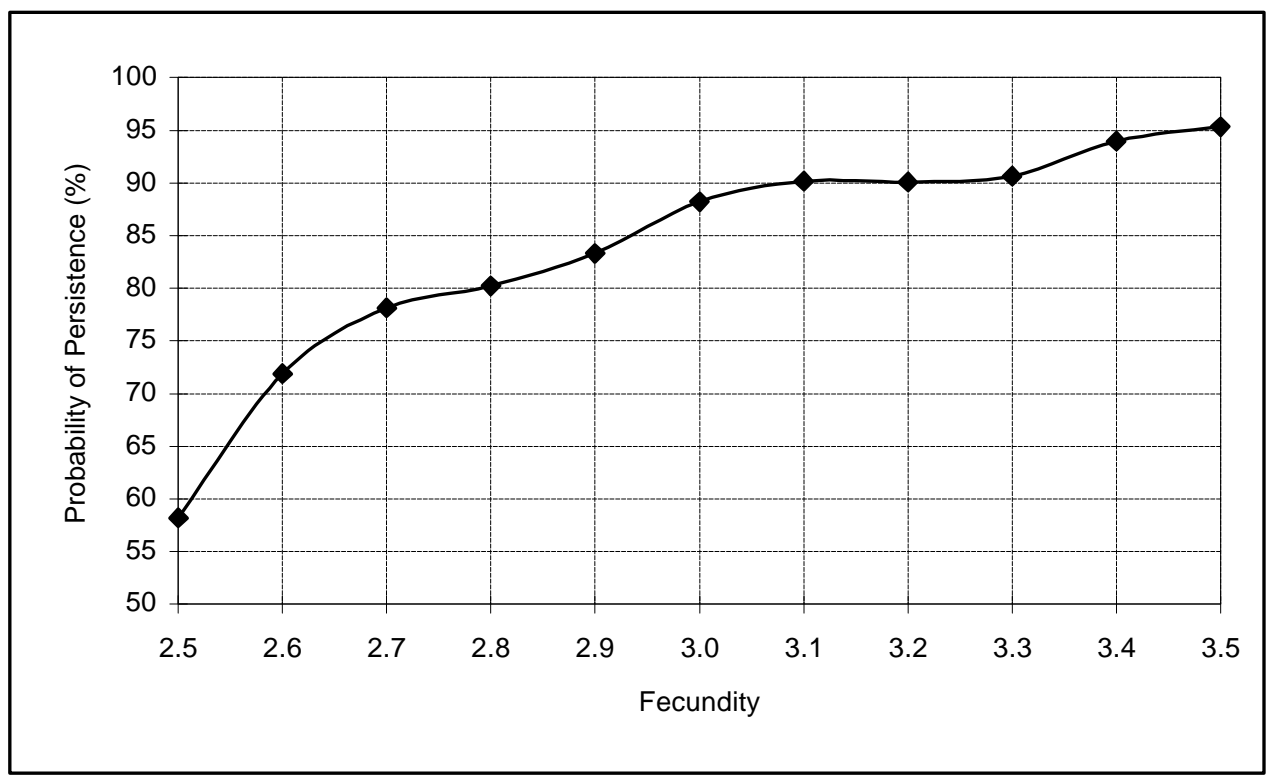

Figure 3. Probability of persistence at the end of 100 years as a function of different levels of fecundity when accounting for uncertainty

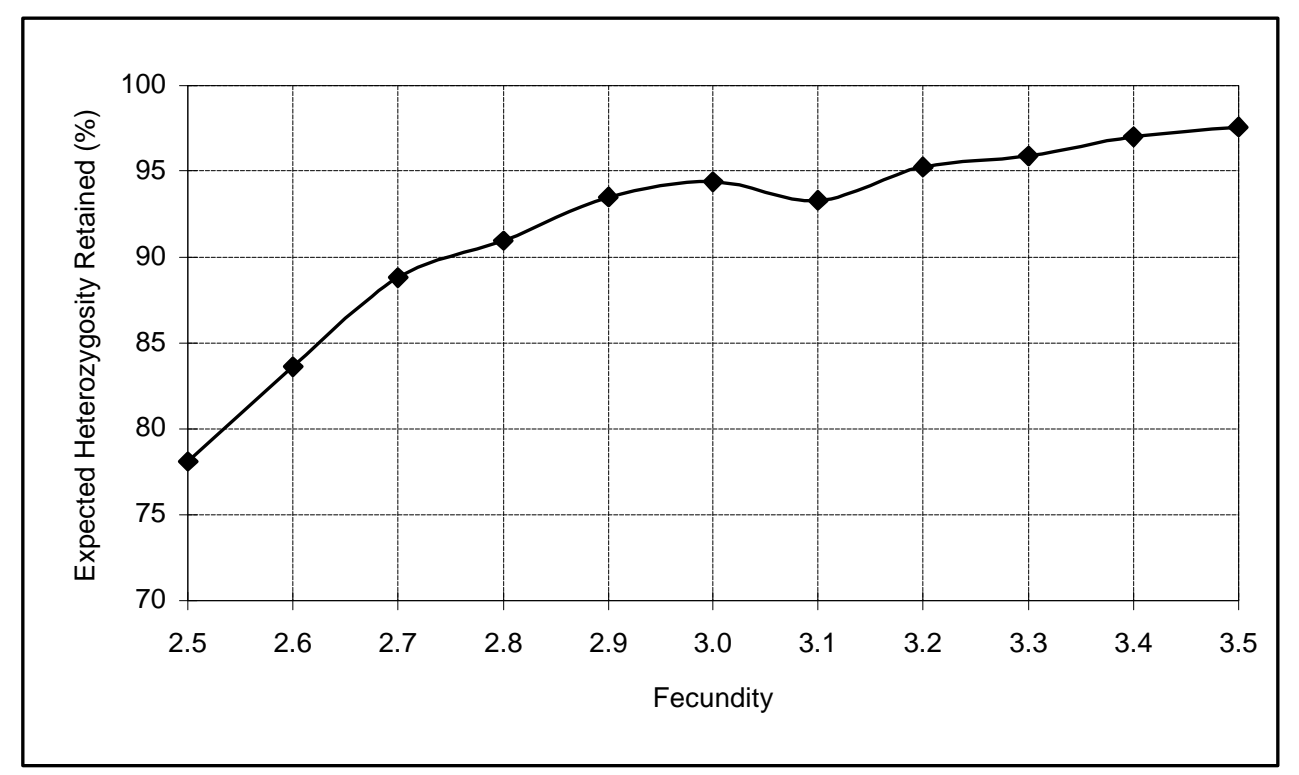

Figure 4. Expected heterozygosity retained at the end of 100 years as a function of different levels of fecundity when accounting for uncertainty 


\section{Discussion}

Results of this study indicate that maintaining habitat conditions as well as improving fecundity rates through management would play a central role in the conservation of this species. Habitat has been declining steadily at least over the last several decades (e.g., Graber 1961, Grzybowski, Tazik, and Schnell 1994). Avoiding additional loss would imply conserving currently suitable habitat as well as replacing portions lost to land-use changes and vegetation succession. Clearly, because this species migrates over the winter, the required carrying capacity should be ensured not only over its breeding grounds but also across its wintering habitat.

Fecundity in the black-capped vireo has decreased largely due to cowbird parasitism (Grzybowski 1995). Management actions successful in reducing this negative impact have included trapping and shooting cowbirds, and destroying cowbird eggs found in black-capped vireo nests (Grzybowski 1990). Additionally, the recovery plan for this species (U.S. Fish and Wildlife Service 1991) recommends an integrated approach to management of land, habitat, and grazing as a basis for reducing cowbird parasitism over the long term. That recovery plan proposes generating large patches of vireo habitat away from the presence of cattle to simultaneously reduce two factors that seem to favor the presence of this parasite: amount of edge and cowbird food in vireo habitat. Lowering the relative abundance of edge should also decrease the negative impact that various nest predators may have on the fecundity of the black-capped vireo. Reducing harassment by birders may also prove important in increasing fecundity rates.

The workshop on viability analysis of the black-capped vireo (U.S. Fish and Wildlife Service 1995) employed the RAMAS program and the no-uncertainty assumption to conduct the PVA simulations. Similar to results obtained in the present study under the no-uncertainty assumption, they concluded that a fecundity of at least 2.5 young fledged per female per year would be necessary to achieve the desired conservation goals. That result arose from analyzing a broad range of possible initial population sizes and variability in survival and fecundity rates. However, that analysis also concluded that any fecundity rate larger than 2.0 young fledged per female per year would be enough to achieve the conservation goals if the initial population size were of similar magnitude to that employed in the present study. Additionally, given the presence of uncertainty in most parameter estimates, the application of those management objectives might prove 
insufficient since the management objectives would be based on an overestimate of our knowledge about the system faced by this species.

Accounting for uncertainty in model parameter estimates is expected to produce uncertainty in model outcomes expressed as a broader distribution of possible future probabilities of persistence and retention of genetic diversity. For that reason, adding uncertainty to the selected conservation scenario under the nouncertainty assumption is likely to produce average results that fall short of the conservation goals. This situation became apparent in the black-capped vireo example. In that case, the high threshold levels of the conservation goals (95 percent persistence and 90 percent genetic retention) were first met by establishing management objectives based on the assumption of no error in estimates of the factors out of management control (Figure 5). However, when error was incorporated (Figure 6), some of the worse-than-average possible combinations of estimates sampled from the error distributions resulted in scenarios that produced probabilities much lower than the acceptable threshold levels for the conservation goals. This circumstance could not be compensated for in the better-than-average combinations sampled from the same distributions since the maximum achievable probability (one) is much closer to the goals than the minimum probability (zero). Only by establishing more demanding objectives than those suggested by the nouncertainty assumption analysis were the conservation goals achieved (Figure 7). Specifically, this example required increasing fecundity by 40 percent (from 2.5 to 3.5 young per female per year) to meet those conservation goals.

Even though the resulting fecundity objective might be unattainable, this approach allowed researchers to quantify the impact of uncertainty in the analysis. That impact may be regarded as the additional cost to achieve the conservation goals as compared to the approach that ignores estimation errors. On the other hand, carrying capacity was always held constant at the estimated current level in the conservation analyses. Clearly, if adequate habitat cannot be maintained, the conservation goals proposed above could not be achieved. Nonetheless, the conservation goals might also have been reached if, instead of assessing only the effect of increasing fecundity rates, different combinations of fecundity and carrying capacity objectives had been evaluated. However, that search would have taken more computational effort than afforded by the resources available during this study. 


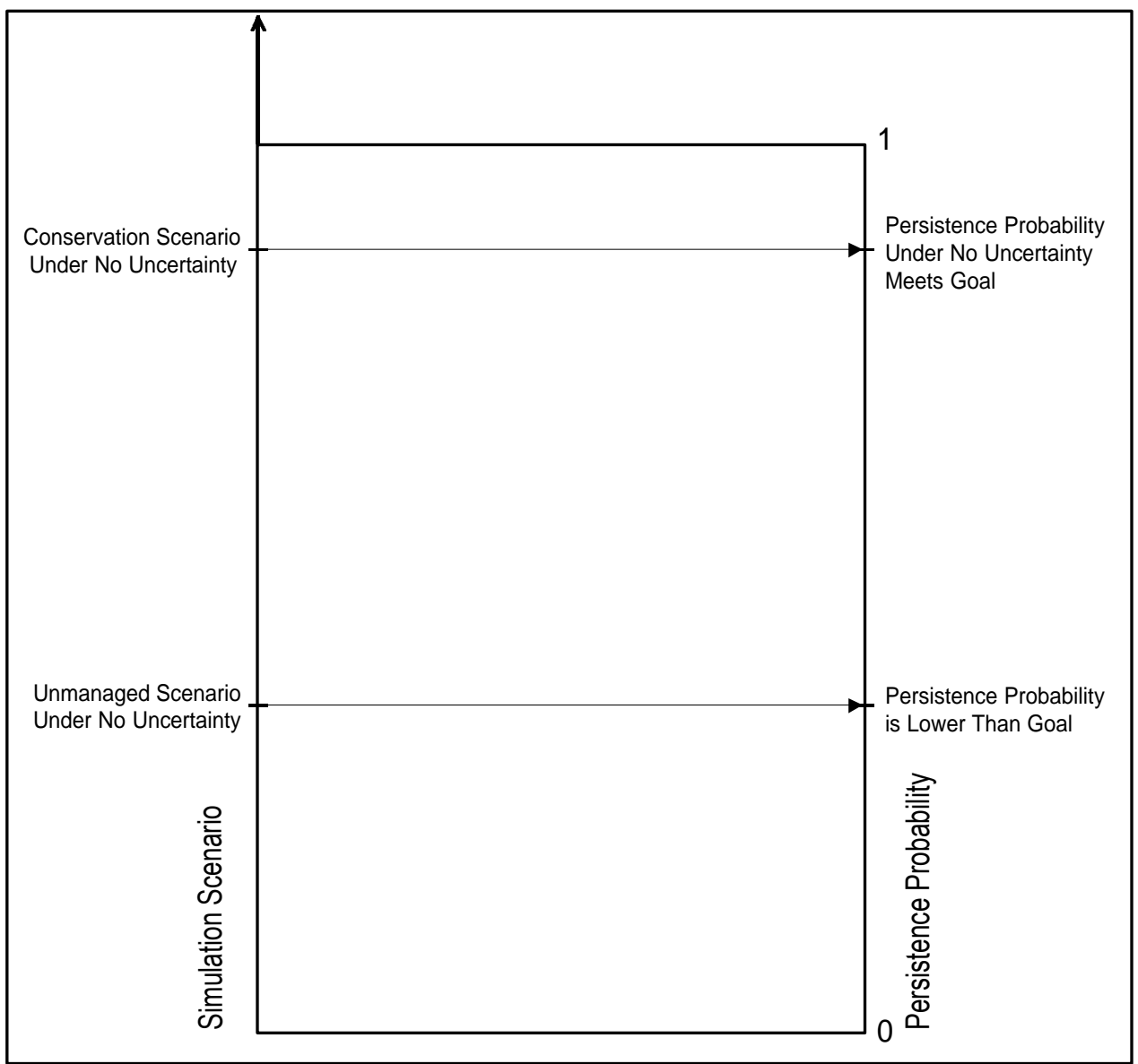

Figure 5. Hypothetical representation of the unmanaged and conservation scenarios with respect to probability of persistence assuming no estimate uncertainty. The more favorable conditions are for the endangered species; the higher the scenario will be located on the "Simulation Scenario" axis. Each scenario will result in a single probability ranging from 0 to 1 on the "Persistence Probability" axis. In the black-capped vireo example, the unmanaged scenario was represented by fecundity $=0.8$ and annual change in carrying capacity $=-2.2 \%$, whereas the conservation scenario by fecundity $=2.5$ and constant carrying capacity. The former scenario did not meet the conservation goal, whereas the latter did 


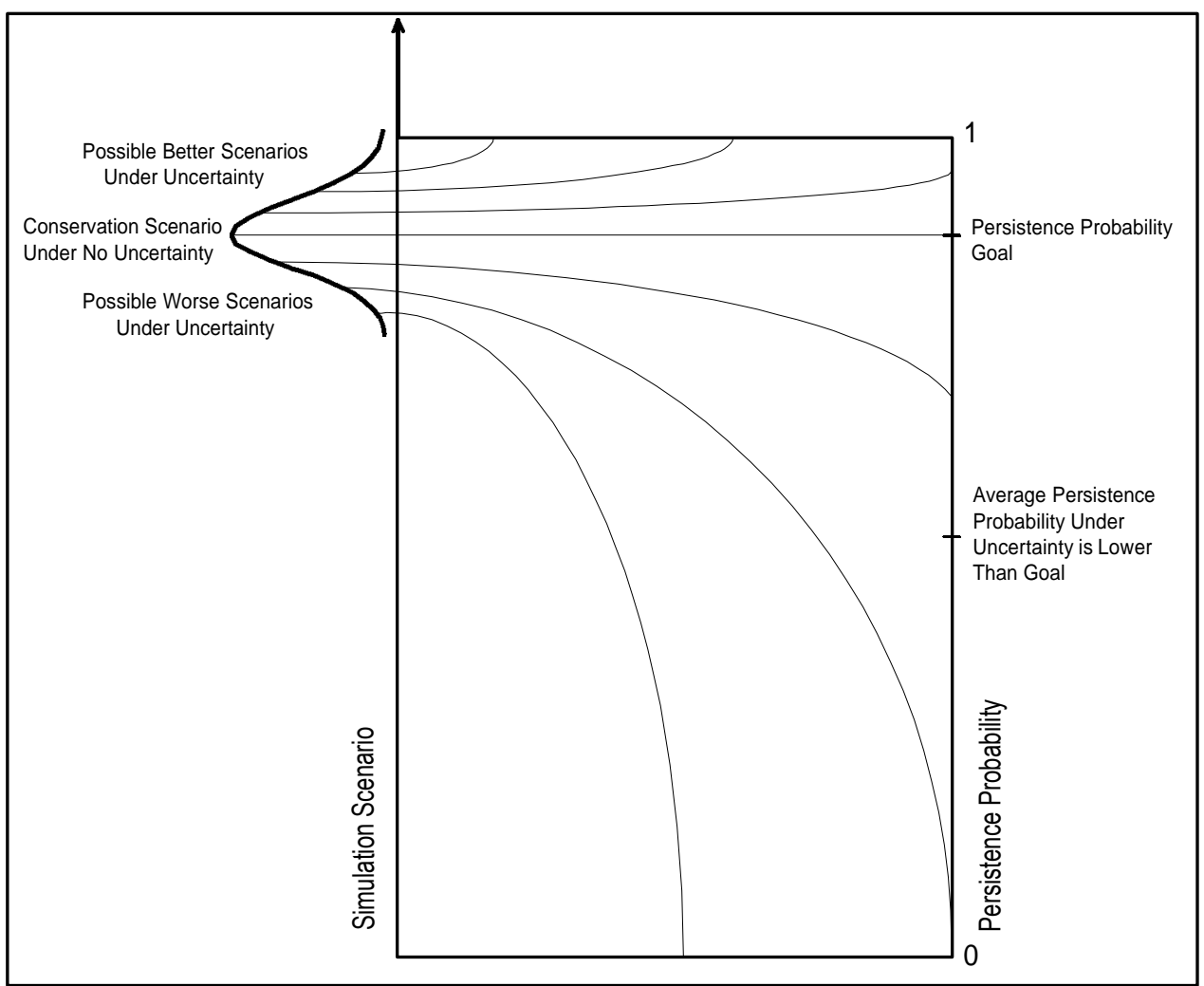

Figure 6. Hypothetical representation of explicitly adding uncertainty in estimates of factors out of management control to the conservation scenario under no uncertainty displayed in Figure 5 (in this study: fecundity $=2.5$ and constant carrying capacity). While pursuing those management objectives, uncertainty will produce multiple possible better and worse scenarios. The overall average probability of persistence resulting from all those scenarios is expected to be lower than the persistence goal, as occurred in the black-capped vireo example 


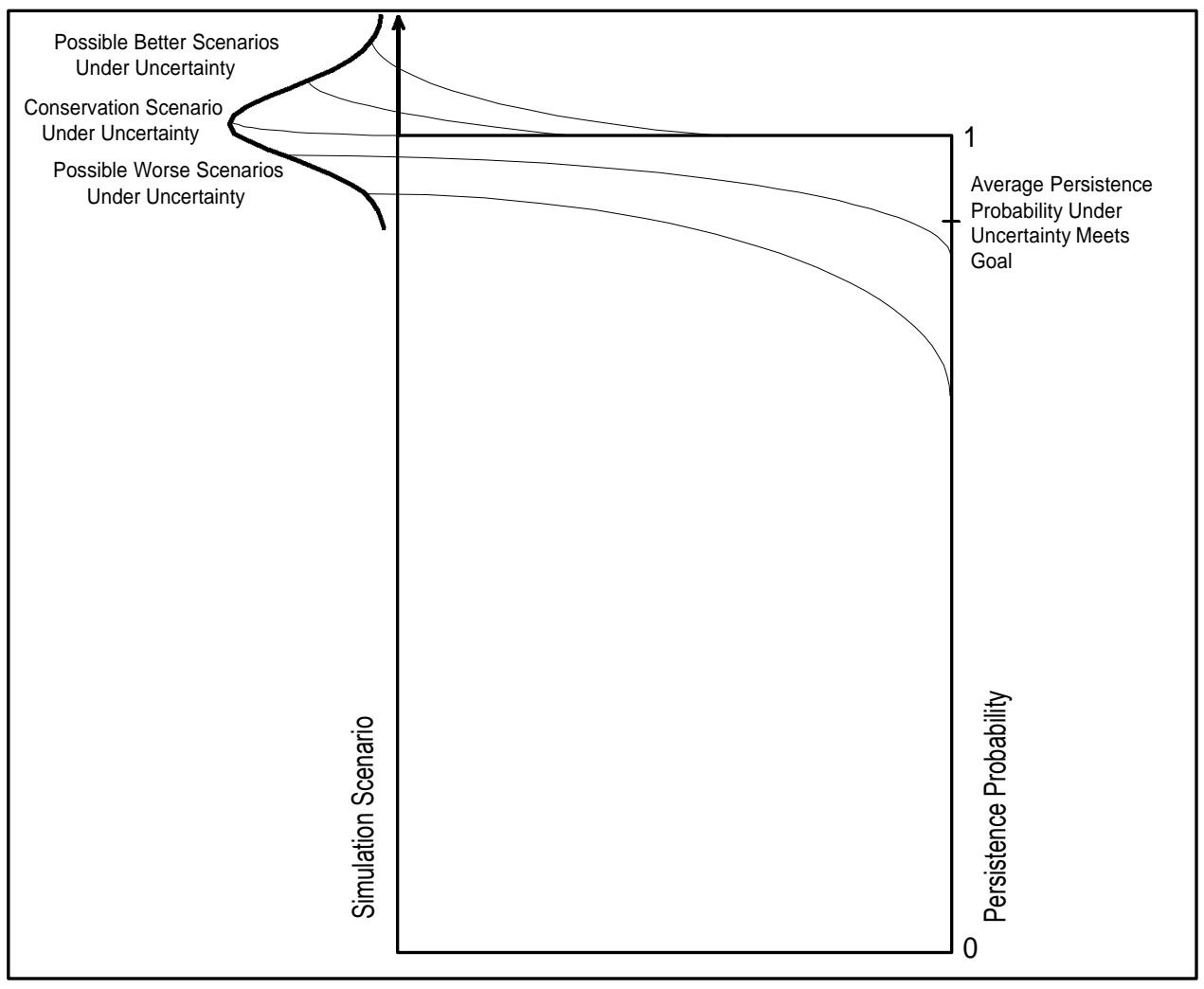

Figure 7. Hypothetical representation of establishing conservation management objectives to achieve the persistence goal in spite of uncertainty in parameter estimates of factors out of management control. By pursuing more demanding management objectives, an overall average probability of persistence that meets the persistence goal will eventually be achieved despite explicitly simulating better and worse possible scenarios generated by uncertainty. In the blackcapped vireo example, the successful conservation scenario under uncertainty was accomplished by fecundity $=3.5$ and constant carrying capacity 


\section{Conclusions/Management Implications}

It can be concluded that the assumption of no uncertainty in parameter estimates of PVA models may lead to an overly optimistic outlook of the species' fate and, therefore, to the establishment of lower management objectives than required to achieve conservation goals. Moreover, the potential for not meeting those goals as uncovered by the explicit simulation of uncertainty can be overcome by implementing more rigorous management objectives, and possibly also by reducing uncertainty about the parameter estimates. Both approaches entail costs that must be assessed in the context of endangered species management plans. The trade-off between costs and uncertainty is a critical element in environmental decision making, yet one that is typically overlooked (Marshall, Haight, and Homans 1998).

The strategy proposed herein is meant to quantify the impact of uncertainty and to provide a tool for enhancing the chances of meeting the conservation goals despite current levels of uncertainty. But what might happen if estimation errors were reduced? Decreasing this uncertainty implies obtaining improved parameter estimates (with lower associated estimation error), which in turn will represent an enhanced knowledge of the system. This new information will depict stochastic and average system conditions for the endangered population that may or may not differ considerably from those previously thought to occur. Therefore, implementation of the analysis proposed herein after incorporating this new information may in turn suggest management objectives that are more or less demanding than those obtained under higher uncertainty. For example, if the condition of the system portrayed by the improved estimates is similar to that under higher uncertainty, the management objectives should be less demanding due to lower error in parameter estimates. If conditions turn out better than under higher uncertainty, the management objectives will be even less rigorous due to both a more favorable system for the species and a lower uncertainty in estimates. However, if conditions happen to be much worse than portrayed by the previous estimates, management objectives may need to be even more demanding than under higher uncertainty. In that case, the reduction in estimation error would not compensate for the realization that the species faces a significantly less favorable system. 
One approach to reducing uncertainty in parameter estimates would consist of improving our knowledge of the estimated values by obtaining information from scientifically sound data collection and experimentation. While natural variability (i.e., demographic, environmental, and genetic stochasticity) cannot be reduced, the precision of our estimates of variability as well as those of other model factors can be improved through such studies. As noted by Bessinger and Westphal (1998), PVA should be applied in conjunction with field studies and experiments designed to identify limiting factors, test hypotheses and evaluate management options. Likewise, sensitivity analysis (McCarthy, Burgman, and Ferson 1995) of the PVA model may help direct studies in a more efficient way by identifying the degree to which different factors affect predictions. All these strategies may be incorporated into an adaptive management approach intended to dynamically improve our understanding of population processes and management decisions for achieving conservation goals. 


\section{References}

Akçakaya, H. R. (1998). "RAMAS/GIS: Linking landscape data with population viability analysis," Applied Biomathematics, Setauket, NY.

Beissinger, S. R., and Westphal, M. I. (1998). "On the use of demographic models of population viability in endangered species management, Journal of Wildlife Management 62, 821-841.

Botsford, L. W., and Brittnacher, J. G. (1998). "Viability of Sacramento River winter-run chinook salmon," Conservation Biology 12, 65-79.

Box, G. E. P., and Tiao, G. C. (1973). Bayesian inference in statistical analysis. Addison-Wesley, Reading, MA.

Boyce, M. S. (1992). "Population viability analysis," Annual Review of Ecology and Systematics 23, 481-506.

Brook, B. W. (2000). "Pessimistic and optimistic bias in population viability analysis," Conservation Biology 14, 564-566.

Brook, B. W., Burgman, M. A., and Frankham, R. (2000). "Differences and congruencies between PVA packages: The importance of sex-ration for predictions of extinction risk," Conservation Ecology 4(1), 6. [online] URL: http//www.consecol.org/vol14/iss1/art6

Brook, B. W., Lim, L., Harden, R., and Frankham, R. (1997). "Does population viability analysis software predict the behaviour of real populations? A retrospective study of the Lord Howe Island Woodhen Tricholimmus sylvestris (Sclater)," Biological Conservation 82, 119-128.

Brook, B. W., O'Grady, J. J., Chapman, A. P., Burgman, M. A., Akçakaya, H. R., and Frankham, R. (2000). "Predictive accuracy of population viability analysis in conservation biology," Nature 404, 385-387.

Burgman, M. A, Ferson, S., and Akçakaya, H. R. (1993). Risk assessment in conservation biology. Chapman and Hall, London.

Caughley, G. (1994). "Directions in conservation biology," Journal of Animal Ecology 63, 215-244. 
Clark, T. W., Backhouse, G. N., and Lacy, R. C. (1991). "Report of a workshop on population viability analysis as a tool for threatened species management and conservation," Australian Zoologist 27, 28-35.

Clark, T. W., Warneke, R. M., and George, G. G. (1990). "Management and conservation of small populations," The management and conservation of small populations. T. W. Clark and J. H. Seebeck, ed., Chicago Zoological Society, Brookfield, IL, 1-18.

Committee on Applications of Ecological Theory to Environmental Problems, National Research Council. (1986). Ecological knowledge and environmental problem solving: Concepts and case studies. National Academy Press, Washington DC.

Crone, E. E., and Gehring, J. L. (1998). "Population viability of Rorippa columbiae: Multiple models and spatial trend," Conservation Biology 12, 1054-1065.

Diamond, J. (1986). "The design of a nature reserve system for Indonesian New Guinea," Conservation Biology, the Science of Scarcity and Diversity. M. E. Soulé, ed., Sinauer, Sunderland, MA, 485-503.

Dobkin, D. S. (1994). Conservation and management of neotropical migrant land birds in the Northern Rockies and Great Plains. University of Idaho Press, Moscow, ID.

Ferson, S. (1990). "RAMAS/stage user manual: Generalized stage-based modeling for population dynamics," Applied Biomathematics, Setauket, NY.

Ferson, S., and Akçakaya, H. R. (1989). "RAMAS/age user manual: Modeling fluctuations in age-structured populations," Applied Biomathematics, Setauket, NY.

Ginzburg, L., Slobodkin, K., Johnson, K., and Bindman, A. G. (1982). "Quasiextinction probabilities as a measure of impact on population growth," Risk Analysis 2, 171-181.

Goovaerts, P. (1997). Geostatistics for natural resources evaluation. Oxford University Press, New York.

Graber, J. W. (1957). "A bioecological study of the black-capped vireo (Vireo atricapilla)," Ph.D. diss., University of Oklahoma, Norman.

(1961). "Distribution, habitat requirements, and life history of the black-capped vireo (Vireo atricapilla)," Ecological Monographs 31, 313336.

Grzybowski, J. A. (1990). "Population and nesting ecology of the black-capped vireo-1990," Resource Protection Division, Texas Parks and Wildlife Department, Austin, TX. 
Grzybowski, J. A. (1995). "Black-capped vireo," The Birds of North America. No. 181, A. Poole and F. Gill, ed., The Academy of Natural Sciences, Philadelphia, and The American Ornithologists' Union, Washington, DC.

Grzybowski, J. A., Tazik, D. J., and Schnell, G. D. (1994). "Regional analysis of black-capped vireo breeding habitats," The Condor 96, 512-544.

Hamilton, S., and Moller, H. (1995). "Can PVA models using computer packages offer useful conservation advice? Sooty Shearwaters Puffinus griseus in New Zealand as a case study," Biological Conservation 73, 107117.

Harris, R. B., Metzger, L. H., and Bevins, C. D. (1986). "GAPPS, Version 3," Montana Cooperative Research Unit, University of Montana, Missoula.

Hogg, R. V., and Tanis, E. A. (1988). Probability and statistical inference. Macmillan, New York.

Kelly, M. J., and Durant, S. M. (2000). "Viability of the Serengeti cheetah population," Conservation Biology 14, 786-797.

Kendall, B. E. (1998). "Estimating the magnitude of environmental stochasticity in survivorship data," Ecological Applications 8, 184-193.

Lacy, R. C. (1993). "VORTEX: A computer simulation model for population viability analysis," Wildlife Research 20, 45-65.

Lindenmayer, D. B., Clark, T. W., Lacy, R. C., and Thomas, V. C. (1993). "Population viability analysis as a tool in wildlife conservation policy: With reference to Australia," Environmental Management 17, 745-758.

Ludwig, D. (1996). "Uncertainty and the assessment of extinction probabilities," Ecological Applications 6, 1067-1076.

Mace, G. M., and Lande, R. (1991). "Assessing extinction threats: Toward a reevaluation of IUCN threatened species categories," Conservation Biology $5,148-157$.

Marmontel, M., Humphrey, S. R., and O'Shea, T. J. (1997). "Population viability analysis of the Florida manatea (Trichechus latirostris), 1976-1991," Conservation Biology 11, 467-481.

Marshall, E., Haight, R., and Homans, E. R. (1998). "Incorporating environmental uncertainty into species management decisions: Kirtland's warbler habitat management as a case study," Conservation Biology 12, 975985.

Mattson, D. J., and Craighead, J. J. (1994). "The Yellowstone grizzly bear recovery program: Uncertain information, uncertain policy," Endangered 
species recovery: Finding the lessons, improving the process, T. W. Clark, R. P. Reading, and A. L. Clarke, ed., Island Press, Washington DC, 101-129.

McCarthy, M. A., Burgman, M. A., and Ferson, S. (1995). "Sensitivity analysis for models of population viability," Biological Conservation 73, 93-100.

Meffe, G. K., and Carroll, C. R. (1994). Principles of conservation biology. Sinauer Associates, Inc., Sunderland, MA.

Mills, L. S., and Smouse, P. E. (1994). "Demographic consequences of inbreeding in remnant populations," American Naturalist 144, 412-431.

Mills, L. S., Hayes, S. G., Baldwin, C., Wisdom, M. J., Citta, J., Mattson, D. J., and Murphy, K. (1996). "Factors leading to different viability predictions for a grizzly bear data set," Conservation Biology 10, 863-873.

Possingham, H. P., and Davies, I. (1995). "ALEX: A model for the viability analysis of spatially structured populations," Biological Conservation 73, 143-150.

Primack, R. (1993). Essentials of conservation biology. Sinauer Associates, Inc., Sunderland, MA.

Ratzlaff, A. (1987). "Endangered and threatened wildlife and plants; Determination of the black-capped vireo to be an endangered species," Federal Register 52, 37420-37423.

Reed, J. M. (1992). "A system for ranking conservation priorities for neotropical migrant birds based on relative susceptibility to extinction," Ecology and conservation of neotropical migrant land birds. J. M. Hagan and D. W. Johnson, ed., Smithsonian Institution Press, Washington and London, 524536.

Rossing, W. A. H., Daamen, R. A., and Jansen, M. J. W. (1994a). "Uncertainty analysis applied to supervised control of aphids and brown rust in winter wheat, Part 1, Quantification of uncertainty in cost-benefit calculations," Agricultural Systems 44 (1994), 419-448.

(1994b). "Uncertainty analysis applied to supervised control of aphids and brown rust in winter wheat, Part 2, Relative importance of different components of uncertainty," Agricultural Systems 44 (1994), 449460 .

Shaffer, M. L. (1987). "Minimum viable populations: Coping with uncertainty," Viable populations for conservation, M. E. Soulé, ed., Cambridge University Press, Cambridge, MA, 69-86.

$39-40$. (1990). "Population viability analysis," Conservation Biology 4, 
Soulé, M. E. (1985). “What is conservation biology?” BioScience 35, 727-734.

. (1987). Viable populations for conservation. Cambridge University Press, Cambridge, MD.

Soulé, M. E., Gilpin, M., Conway, W., and Foose, T. (1986). "The millennium ark: How long a voyage, how many staterooms, how many passengers?" Zoo Biology 5, 101-114.

Taylor, B. L. (1995). "The reliability of using population viability analysis for risk classification of species," Conservation Biology 9, 551-558.

Tazik, D. J. (1991). "Proactive management of an endangered species on Army lands: The black-capped vireo on the lands of Fort Hood, Texas," Ph.D. diss., University of Illinois, Urbana-Champaign, Urbana, IL.

U.S. Fish and Wildlife Service. (1991). "Black-capped vireo (Vireo atricapillus) recovery plan," Austin, TX.

. (1995). "Black-capped vireo population and habitat viability assessment report," Compiled and edited by Carol Beardmore, Jeff Hatfield, and Jim Lewis in conjunction with workshop participants, Report of a September 19-21, 1995, workshop arranged by the U.S. Fish and Wildlife Service in partial fulfillment of U.S. National Biological Service Grant No. 80333-1423, Austin, TX.

White, G. C. (2000). "Population viability analysis: Data requirements and essential analyses," Research techniques in animal ecology: Controversies and consequences. L. Boitani and T. K. Fuller, ed., Columbia University Press, New York, 288-331. 


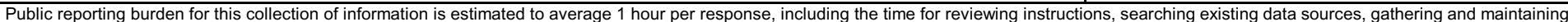

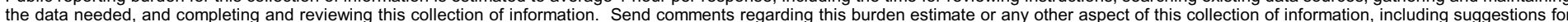

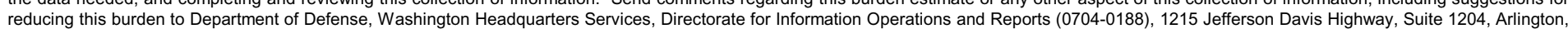

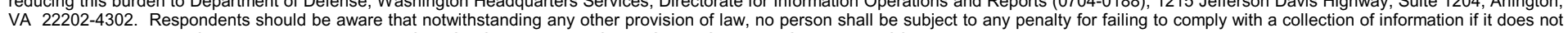
display a currently valid OMB control number. PLEASE DO NOT RETURN YOUR FORM TO THE ABOVE ADDRESS.

\begin{tabular}{l|c}
$\begin{array}{l}\text { 1. REPORT DATE (DD-MM-YYYY) } \\
\text { August } 2001\end{array}$ & $\begin{array}{c}\text { 2. REPORT TYPE } \\
\text { Final report }\end{array}$ \\
\hline
\end{tabular}

\section{TITLE AND SUBTITLE}

Assessing the Effect of Estimation Error on Population Viability Analysis: An Example Using the Black-Capped Vireo

3. DATES COVERED (From - To)

5a. CONTRACT NUMBER

5b. GRANT NUMBER

5c. PROGRAM ELEMENT NUMBER

5d. PROJECT NUMBER

5e. TASK NUMBER

5f. WORK UNIT NUMBER

8. PERFORMING ORGANIZATION REPORT NUMBER

ERDC/EL MP-01-1

U.S. Army Engineer Research and Development Center, Environmental Laboratory, 3909 Halls Ferry Road, Vicksburg, MS 39180-6199

Vicksburg,

Flagstaff, AZ 86011

\section{SPONSORING / MONITORING AGENCY NAME(S) AND ADDRESS(ES)}

U.S. Army Corps of Engineers

Washington, DC 20314

10. SPONSOR/MONITOR'S ACRONYM(S)

11. SPONSOR/MONITOR'S REPORT NUMBER(S)

\section{DISTRIBUTION / AVAILABILITY STATEMENT}

Approved for public release; distribution is unlimited.

\section{SUPPLEMENTARY NOTES}

\section{ABSTRACT}

Population viability analysis (PVA) usually assumes that the values of factors that characterize average conditions as well as natural variability (stochasticity) are error-free. However, those values are often estimates of true parameters and, therefore, have an associated estimation error. This error, also referred to as uncertainty, arises from limitations of the methods used to estimate parameter values, such as sampling, measurement, and expert opinion error. Natural resource management decisions must be made in spite of incomplete information; therefore, the impact of uncertainty when establishing specific management objectives must be assessed. A strategy is proposed here to account for error in parameter estimates of PVA models and to assess the strategy's effect on establishment of endangered species conservation objectives. Using the computer simulation model VORTEX, this strategy was applied to the blackcapped vireo (Vireo atricapillus), an endangered neotropical migrant land bird species. The two conservation goals used in this study were probability of persistence and retention of genetic diversity of at least 95 percent and 90 percent, respectively, over the next 100 years. Two situations were evaluated, one accounting for uncertainty, the other not. Achieving the conservation goals while explicitly accounting for estimate uncertainty required more demanding management objectives than that assuming no uncertainty. Under static carrying capacity, fecundity had to be increased 40 percent from 2.5 to 3.5 young fledged per female per year to meet the conservation goals. By explicitly incorporating estimation error, the range of possible circumstances and outcomes (Continued)
15. SUBJECT TERMS
Black-capped vireo
Endangered species
Estimation error
Conservation biology
Neotropical migrant
Population viability analysis (PVA) Uncertainty
VORTEX

16. SECURITY CLASSIFICATION OF:

Neotropical migrant

\section{a. REPORT}

Unclassified

b. ABSTRACT
Unclassified

\section{c. THIS PAGE}

Unclassified

\section{LIMITATION \\ 19a. NAME OF RESPONSIBLE} OF ABSTRACT PERSON

18. NUMBER
OF PAGES
29

19b. TELEPHONE NUMBER (include area code) 


\section{Abstract (continued)}

faced by a given species can be assessed in a way that reflects current knowledge about stochastic and average system conditions. This in turn allows identification of measures necessary to enhance the likelihood of meeting conservation goals in spite of that level of uncertainty, and establishment of a base for targeting further experimentation and data collection to reduce this type of error. 